\title{
ANÁLISE DE ALGUNS EQUÍVOCOS E DISTORÇÕES PRESENTES EM SITES DA WEB E VÍDEOS DO YOUTUBE SOBRE A LEI DA INDUÇÃO ELETROMAGNÉTICA DE MICHAEL FARADAY
}

\author{
Analysis of some Misconceptions and Distortions presents on Web Sites and YouTube \\ Videos on Michael Faraday's Electromagnetic law
}

\author{
Renan André Peres* \\ Luciano Carvalhais Gomes**
}

\begin{abstract}
Resumo: Neste artigo, apresentamos algumas reflexões decorrentes de nossa pesquisa que teve como principal objetivo responder ao seguinte questionamento: Quais os equívocos e distorções existentes na apresentação do conteúdo da lei da Indução Eletromagnética de Michael Faraday (lei de Faraday) em sites da web e vídeos do YouTube? Nossa investigação envolveu uma breve revisão histórica sobre a lei de Faraday e uma análise de como esse tópico é apresentado em sites da web e vídeos do YouTube. Para isso, empregamos os procedimentos metodológicos de pesquisa bibliográfica conforme descritos por Salvador (1981), uma vez que tínhamos como objetivo compreender, analisar e confrontar criticamente um determinado conteúdo de diversas fontes bibliográficas. Em síntese, podemos afirmar que a lei da Indução Eletromagnética de Michael Faraday, conforme apresentada nos sites e vídeos analisados, difere da que o britânico enunciou em 1832, em seu primeiro artigo da série Pesquisas Experimentais em Eletricidade e, posteriormente, em outros textos.
\end{abstract}

Palavras-chave: Lei de Faraday. Sites da Web. Vídeos do YouTube. Equívocos e Distorções.

\begin{abstract}
We present in this article some reflections as a result of our research, which had as main goal to answer the following question: What are the different misconceptions and distortions that exist in presenting the content of Michael Faraday Electromagnetic law (Faraday's law) on web sites and YouTube videos? Our research involved mainly in a brief historical review about Faraday's law and an analysis about how this topic is presented on web sites and YouTube videos. For this, we use the methodological procedures of bibliographic research as described by Salvador (1981), since we aimed to understand, analyze and critically confront a given content from several bibliographic sources. To sum up, we can affirm that Michael Faraday's law of Electromagnetic Induction, as displayed on the reviewed sites and videos, is different from what the British enunciated in 1832, in his first article of the series named the Experimental Research on Electricity, and later on in other texts.
\end{abstract}

Keywords: Faraday's law. Web Sites. YouTube Videos. Misconceptions and distortions.

\footnotetext{
* * Mestre em Educação para a Ciência e a Matemática pela Universidade Estadual de Maringá. Orcid: 0000-00015868-1118. E-mail: renan_321_321@ hotmail.com

** Doutor em Educação para a Ciência e a Matemática e professor adjunto na Universidade Estadual de Maringá. Orcid: 0000-0002-2005-9224. E-mail: lcgomes2@uem.com.br
} 


\title{
1 Introdução
}

A cada ano que passa, novos e revolucionários produtos tecnológicos são lançados no mercado, impactando também no avanço da Tecnologia Digital da Informação e Comunicação (TDIC). Desse modo, o sistema de ensino está constantemente sendo pressionado para acompanhar e aproveitar da melhor maneira possível esse desenvolvimento. Segundo Pereira et al. (2012):

\begin{abstract}
A acelerada evolução das tecnologias, a exemplo da Internet, tem proporcionado um rápido e fácil acesso a informação. [...] os recursos da Internet aplicados no ambiente educativo podem contribuir qualitativamente no desenvolvimento de novas atitudes educacionais (PEREIRA et al. 2012, p. 2).
\end{abstract}

Com relação à Internet, surge a preocupação quanto à credibilidade dos conteúdos e informações que estão sendo apresentados, uma vez que "[...] através da Internet são publicados e distribuídos textos que escapam à avaliação e ao controle de qualidade, controle dos conselhos editoriais" (BARRETO, 2010, p. 85). Nesse contexto, a presente pesquisa buscou responder ao seguinte questionamento: Quais os equívocos e distorções existentes na apresentação do conteúdo da lei de Faraday em sites da web e vídeos do YouTube?

Para isso, e tendo em vista o imprescindível papel da História da Ciência para o desenvolvimento de um Ensino de Ciências mais envolvente, dinâmico, reflexivo, crítico e humanizado, tal como defendido por alguns autores como Martins (2001, 2006), Barros e Carvalho (1998), Carvalho (1992, 2008), Matthews (1995) e Neves (1998), buscamos construir e apresentar uma revisão histórica mais concisa e fidedigna possível com relação ao episódio histórico em questão.

Apresentaremos, neste artigo, os resultados encontrados em nossa investigação, que envolveu uma breve revisão histórica sobre a lei de Faraday e uma análise de como esse tópico é apresentado em sites da web e vídeos do YouTube.

A título de sustentação a nossa investigação, salientamos que trabalhos semelhantes a mesma, ou seja, análises críticas sobre interpretações atuais à luz de reconstruções históricas e análises de trabalhos originais, também já podem ser encontrados na literatura. Para exemplificar, temos o trabalho de Ribeiro (2008), que apresentou uma análise histórica a respeito das concepções de 'campo' no Eletromagnetismo do século XIX, inclusive de Michael Faraday, e analisou a atual interpretação desse mesmo tema em livros didáticos, demonstrando o quão distante e distorcido o conceito de 'campo' passou a ser apresentado e utilizado com relação a suas origens e referências históricas, e mostrou que há incoerências "[...] em livros didáticos de graduação e pós-graduação em Física no que se refere a aplicação do termo campo" (RIBEIRO, 2008, p. 49).

Além da investigação acima citada, encontramos também outro trabalho nessa mesma linha em Gomes (2008), em que, após desenvolver uma reconstrução histórica sobre a relação entre força e movimento e identificar as concepções alternativas acerca do tema presentes em uma revista de divulgação científica, observou na mesma "[...] vários erros conceituais; imprecisão na utilização de conceitos científicos, principalmente, força e energia; definições de leis físicas de forma inadequadas; entre outros equívocos" (GOMES, 2008, p. 114). 


\section{Percurso metodológico}

Levando em consideração que para o alcance de nossos objetivos seria necessário uma intensa prática de leitura e análise crítica sobre um conteúdo em diversas obras e fontes bibliográficas, optamos por empregar a metodologia da pesquisa bibliográfica, uma vez que desenvolver uma pesquisa bibliográfica "[...] significa realizar um movimento incansável de apreensão dos objetivos, de observância das etapas, de leitura, de questionamentos e de interlocução crítica com o material bibliográfico, e que isso exige vigilância epistemológica"

(LIMA; MIOTO, 2007, p. 37).

Para o desenvolvimento de um percurso metodológico melhor traçado, conciso e direcionado, tivemos como principal aporte teórico a sequência dos procedimentos metodológicos conforme descritos por Salvador (1981), ao discorrer sobre a pesquisa bibliográfica, constituída de quatro fases: a Elaboração do Projeto de Pesquisa, Investigação das Soluções, Análise Explicativa das Soluções e a Síntese Integradora.

Desta forma, a primeira fase de nossa investigação foi a Elaboração do Projeto de Pesquisa, o momento inicial no qual escolhemos o assunto, delimitamos o problema pesquisa e definimos os objetivos.

Após a elaboração do projeto de pesquisa, nossa investigação ocorreu em três momentos: o Reconhecimento inicial e familiarização com o ambiente da pesquisa, a Pesquisa histórica-conceitual e a Pesquisa em sites da web e vídeos do YouTube. Sendo que as três fases seguintes de Salvador (1981) ocorreram dentro de tais momentos por nós estabelecidos.

Após o primeiro momento, iniciamos a segunda fase estabelecida por Salvador (1981), a Investigação das Soluções, um momento crucial da pesquisa bibliográfica, uma vez que se traduz em uma das fases:

[...] decisivas da realização de um estudo científico [em especial da pesquisa bibliográfica]. Trata-se da coleta da documentação. Os resultados da pesquisa dependem da quantidade e, sobre tudo, da qualidade dos dados coletados. É tarefa estafante, quase braçal, que exige muita paciência e persistência, como também certos conhecimentos e certas técnicas (SALVADOR, 1981, p. 73).

Devido ao fato dessa fase ser constituída basicamente de uma intensiva prática de leitura, Salvador (1981) nos oferece alguns processos de leitura que podem ser adotadas na seguinte ordem: Leitura de reconhecimento do material bibliográfica, Leitura exploratória, Leitura seletiva, Leitura reflexiva ou crítica e, por último, a Leitura interpretativa. Assim, em nosso primeiro momento, o 'Reconhecimento inicial e familiarização com o ambiente da pesquisa', realizamos o primeiro processo de leitura, ou seja, uma breve pesquisa sobre algumas fontes com o intuito de haver uma familiarização com o tema e os materiais que seriam investigados, tanto para a Pesquisa histórica-conceitual quanto para a Pesquisa em sites da web e vídeos do YouTube.

Com exceção do primeiro processo de leitura, os demais, tal como o desenvolvimento das próximas fases de Salvador (1981), ocorrem em duplicidade, uma vez que fora necessário realizar duas pesquisas bibliográficas em tempos distintos, ou seja, primeiro foi necessário desenvolver a investigação histórica sobre a lei de Faraday, para que então pudéssemos realizar a análise de tal conteúdo em sites da web e vídeos do YouTube, pois utilizamos a pesquisa histórica como referência e aporte teórico para a detecção dos equívocos nessa última. 
Assim, em nosso segundo momento, denominado 'Pesquisa histórica-conceitual', realizamos nossa investigação e análise histórica sobre a lei de Faraday, um momento onde finalizamos a fase de Investigação das Soluções (e apenas da pesquisa histórica) selecionando os materiais e conteúdos mais relevantes (ocorrendo ao mesmo tempo uma análise prévia para tal atribuição) com relação aos nossos objetivos. Para isso, analisamos previamente e selecionamos algumas das principais obras de Faraday sobre o assunto, em especial, alguns de seus artigos da série Experimental Researches in Electricity [Pesquisas Experimentais em Eletricidade] (1832-1855).

Ainda nesse momento da Pesquisa histórica-conceitual, desenvolvemos também a fase da Análise Explicativa das Soluções, e apenas da pesquisa histórica, ou seja, foi o ponto no qual desenvolvemos nossas interpretações, reflexões e análises mais minuciosas sobre as ideias e os fatos trazidos pelo autor investigado, nesse caso, sobre a lei de Faraday e seu fundamental contexto filosófico. É nessa fase em que buscamos construir e apresentar discussões e argumentos em defesa de nossa tese, visando explicar os fatos da maneira mais fidedigna possível para o alcance de nossos objetivos. Assim como reforça Salvador (1981, p. 144), “[...] os fatos, dados e informações necessitam serem explicados em relação às suas origens ou causas, em sua natureza íntima e em seus efeitos ou finalidades".

No terceiro momento geral de nossa investigação, a 'Pesquisa em sites da web e vídeos do YouTube', desenvolvemos uma pesquisa bibliográfica sobre a lei de Faraday em alguns sites e vídeos selecionados mediante alguns critérios, como será melhor apresentado logo à frente. Nesse momento, assim como na pesquisa histórica-conceitual, também desenvolvemos as fases de Investigação das Soluções e da Análise Explicativa das Soluções.

Feito o levantamento dos sites e vídeos a serem analisados, assim como dos conteúdos a serem focados, realizamos uma análise minuciosa e um confronto crítico dos mesmos com a revisão histórica realizada anteriormente, para que então fôssemos capazes de identificar e compreender os equívocos e distorções presentes. Com o desenvolvimento e a apresentação das reflexões e discussões, finalizamos a fase de Análise Explicativa das Soluções da Pesquisa em sites da web e vídeos do YouTube.

Por último, no terceiro momento geral, tivemos a fase da Síntese Integradora, ou seja, a fase final da pesquisa em que buscamos desenvolver nossas conclusões e construir uma síntese integrada dos resultados encontrados (Quadro 3), uma vez que há necessidade de "[...] elaborar uma síntese que integre, ordenada, coordenada e subordinadamente todas as soluções encontradas" (SALVADOR, 1981, p. 168) para que sejamos capazes de retornar ao nosso problema de pesquisa com as soluções emergentes de toda a investigação, em nosso caso, os equívocos detectados na apresentação da lei de Faraday e as discussões acerca dos mesmos.

\section{Uma breve revisão histórica sobre a lei da Indução Eletromagnética de Michael Faraday: sobre o seu enunciado de 1832}

Antes de adentrarmos especificamente na lei de Faraday, vale salientar que, anteriormente a seu sucesso na Indução de Corrente Elétrica em 1831 e o desenvolvimento de sua lei, Michael Faraday (1791-1867) já possuía uma caminhada com mais de 10 anos no campo do Eletromagnetismo (ainda não denominado dessa maneira na época), caminhada essa que teve o seu início em 1821, um ano após a divulgação do experimento de Ørsted (experimento da agulha imantada), que consistia na deflexão de uma agulha imantada no momento em que um fio retilíneo percorrido por uma corrente elétrica era aproximado paralelamente a ela. 
Lembremos que, no final do século XVIII, muitos cientistas ainda criam na completa distinção entre as naturezas dos fenômenos magnéticos e elétricos e levantavam não haver qualquer tipo relação entres os mesmos, como Benjamin Franklin (1706-1790) que, ao comentar sobre o assunto, levantou: "Em relação ao magnetismo, que parece ser produzido pela eletricidade, minha opinião real é que esses dois poderes da natureza não possuem afinidade mútua, e que a aparente produção do magnetismo [pelas descargas elétricas] é puramente acidental" (FRANKLIN, 1773 in: MARTINS, 1986).

Contudo, com o surgimento de algumas correntes filosóficas no fim do século XVIII, como a alemã Naturphilosophie, a crença de que o magnetismo e a eletricidade eram acontecimentos provenientes de uma mesma natureza já motivava muitos cientistas a buscarem por indícios mais sólidos que "comprovassem" a relação eletromagnética. Como era o caso de Hans Christian Ørsted (1777-1851), adepto a essa corrente filosófica que tinha com princípio a ideia de que todo o universo estaria conectado de alguma maneira e, dessa forma, todos os fenômenos observados teriam um causador comum (GARDELLI, 2014).

Assim, motivado a buscar fatos experimentais que corroborassem a existência do Eletromagnetismo, sobretudo pelo princípio filosófico "[...] de que todos os fenômenos são produzidos pelo mesmo poder original" (ØRSTED, 1830, p. 575, tradução nossa), Ørsted e "[...] sua constante persistência na busca de sua ideia, tanto por raciocínio e experimento, foi bem recompensada no inverno de 1819" (FARADAY, 1821, p. 195, tradução nossa), através do experimento da agulha imantada, experimento que possibilitou uma percepção mais clara da interação eletromagnética até o momento.

Enfim, depois desse experimento ter sido apresentado ao mundo, em 21 de julho de 1820 (SNELDERS, 1990), Faraday, assim como muitos, tomou grande interesse pelo tema, iniciando suas próprias pesquisas nessa mais nova área da ciência que estava a se desenvolver, trazendo importantes pesquisas e resultados logo no início de seus trabalhos, como por exemplo, o seu sucesso nas Rotações Eletromagnéticas.

Após alguns anos de pesquisas no Eletromagnetismo, mais especificamente em 1828, registros em seu diário de laboratório mostram que Faraday já buscava uma possível Indução de Corrente Elétrica a partir de imãs naturais. Contudo, a ausência de resultados positivos em tal período fez com que ele permanecesse afastado do Eletromagnetismo até o ano de 1831, ano em que viria obter êxito em seus experimentos de Indução de Corrente Elétrica. No dia 29 de agosto de 1831, aconteceu o primeiro contato de Faraday (ou que pelo menos que ficou registrado) com a Indução de Corrente Elétrica (MARTINS, 1949; THOMPSON, 1898; JONES, 1870; DIAS, 2004), fato esse que seria apenas o começo de uma longa série de pesquisas e resultados de suma importância para essa área.

Com o desenvolvimento e aprofundamento de suas pesquisas, Faraday conseguiu chegar a diversos feitos e resultados importantes, como a indução contínua de corrente elétrica a partir do magnetismo comum, fato esse que se tornou possível por meio do experimento ilustrado na Figura 1. 
Figura 1 - Na esquerda, esboço do experimento que possibilitou Faraday induzir corrente elétrica de maneira contínua a partir do magnetismo comum (presente em seu diário), e na direita, uma ilustração do mesmo experimento (presente em seu artigo).
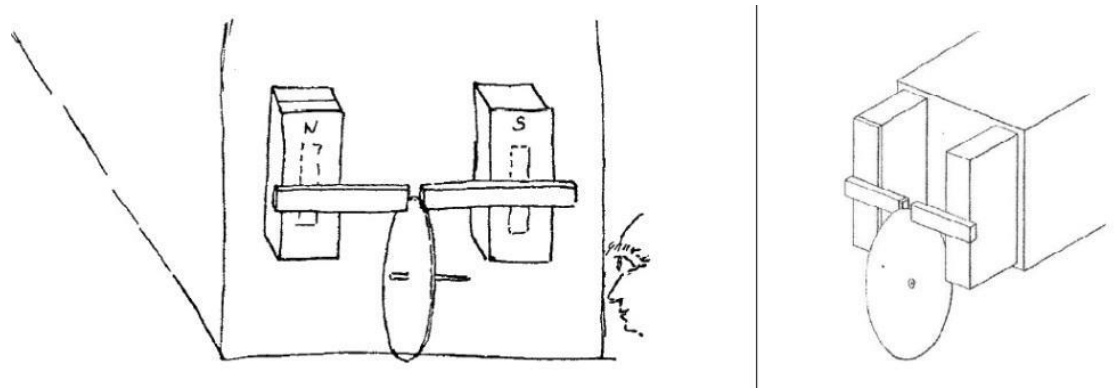

Fonte: Compilação dos autores ${ }^{1}$.

O período entre o mês de agosto e novembro de 1831 é marcado por um intenso avanço e progresso de Faraday em suas pesquisas e experimentos, possibilitando-o chegar em significativas reflexões e conclusões na área do Eletromagnetismo, como a sua própria lei da Indução Eletromagnética, que foi apresentada no primeiro artigo de sua série Experimental Researches in Electricity [Pesquisas Experimentais em Eletricidade], publicado em 1 de janeiro de 1832.

Nesse artigo, Faraday fez diversas reflexões quanto ao comportamento da corrente elétrica induzida, em especial, quanto às suas direções ${ }^{2}$ em cada situação e o caráter ortogonal que a mesma apresentava com relação ao movimento do condutor, dois aspectos esses tratados em sua lei. Ao início do trabalho, ele já procurou deixar claro sobre a existência de uma lei para compreender os efeitos da Indução Eletromagnética, efeitos que seriam "42 [...] simples consequências da lei a ser descrita adiante (114)" (FARADAY, 1832, p. 135, tradução nossa). No entanto, a mesma seria apresentada apenas mais adiante em seu artigo, especificamente no parágrafo 114 (Faraday adotava uma prática de enumeração dos parágrafos em seus trabalhos). Assim, a lei que rege o comportamento da Indução de Corrente Elétrica a partir do magnetismo comum fora apresentada por Faraday da seguinte maneira:

114. A relação mantida entre o polo magnético, o fio ou metal em movimento, e a direção da corrente elétrica desenvolvida, isto é, a lei que governa a evolução da eletricidade pela indução eletromagnética, é muito simples, embora difícil de expressar. Se na fig. 24 [Figura 2], PN representa um fio horizontal passando por um polo marcado, de tal modo que a direção de seu movimento deva coincidir com a linha curvada procedendo de baixo para cima; ou se, seu movimento paralelo a si mesmo seja em uma linha tangencial a da linha curvada, mas na direção geral das setas; ou se ele passa o polo em outras direções, mas de tal modo a cortar as curvas magnéticas* na mesma direção geral, ou sobre o mesmo lado no qual elas seriam cortadas pelo o fio se movimentado ao longo da linha curva pontilhada; então a corrente de eletricidade no fio vai de P para N. Se ele [o fio] for movimento em direção inversa, a [direção da] corrente de eletricidade será de N para P. Ou se o fio estiver em posição vertical, representado por P'N', e ele for movimentado em direções similares, coincidindo com a curva horizontal pontilhada, de tal modo a cortar as curvas

\footnotetext{
${ }^{1}$ Imagens retiradas do diário de Faraday (in: MARTINS, 1932-36, p. 381) e também de seu primeiro artigo da série Pesquisas Experimentais em Eletricidade, publicado originalmente em 1832 (in: FARADAY ,2011, p. 181).

2 Na época, o termo 'direção' apresentava o mesmo significado do que conhecemos hoje como 'sentido', dessa forma, utilizou-se nesse artigo o termo ‘direção’ com o mesmo significado da época.
} 
magnéticas sobre o mesmo lado que ela, a [direção da] corrente será de P' para N'. Se o fio for considerado uma tangente à superfície curvada do imã cilíndrico, e ele for movimentado ao redor dessa superfície em qualquer outra posição, ou se o próprio imã for girado em torno de seu eixo, de tal modo a trazer qualquer parte oposta ao fio tangente, ainda, se depois o fio for movido nas direções indicadas, à [direção da] corrente de eletricidade será de $\mathrm{P}$ para $\mathrm{N}$; ou se ele for movido na direção oposta, de $\mathrm{N}$ para $\mathrm{P}$; de modo que, nos diz respeito aos movimentos do fio passados pelo polo, eles podem ser reduzidos a dois [tipos de movimentos], diretamente opostos um ao outro, um deles que produz uma corrente de $\mathrm{P}$ para $\mathrm{N}$, e o outro, [uma corrente] de $\mathrm{N}$ para $P$ (FARADAY, 1832, p. 154-5, tradução nossa).

Figura 2 - Esquema elaborado por Faraday para a apresentação de sua lei da Indução Eletromagnética (presente no artigo)

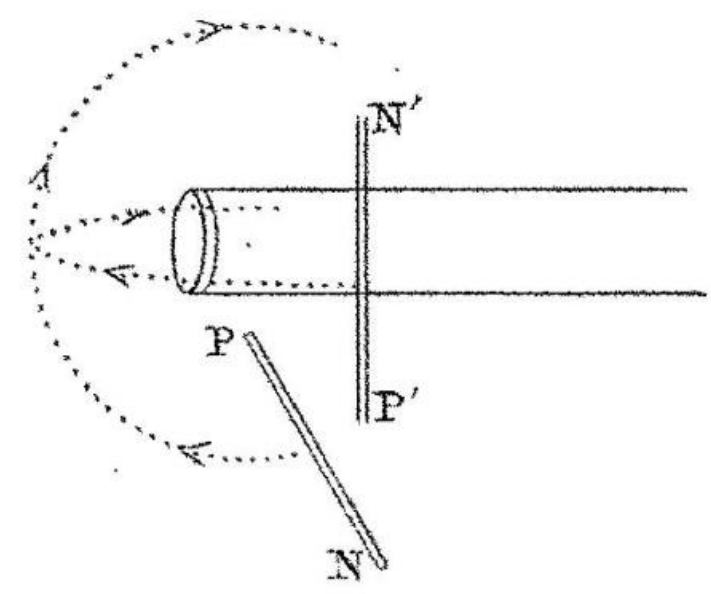

Fonte: FARADAY (2011).

De início, podemos observar que Faraday conseguiu encontrar uma situação em que fosse possível observar bem os efeitos da Interação Eletromagnética a partir de diversas perspectivas, conforme descrita e representada na Figura 2. Em suma, notamos que o seu objetivo foi representar de maneira geral a direção e o comportamento ortogonal da corrente elétrica induzida, a partir de casos distintos, simulando movimentos de um condutor retilíneo em torno de um dos polos magnéticos de um imã cilíndrico, nesse caso, do polo marcado (polo Norte).

No primeiro caso, o pesquisador inglês observou o comportamento da corrente elétrica a partir do movimento de um fio horizontal (PN) em torno do polo magnético, fazendo com que esse fosse levado de baixo para cima, conforme indicado pelas setas na Figura 2. Nesse caso, a direção da corrente elétrica no fio seria de P para N. Já se o movimento fosse inverso, ou seja, o fio horizontal fosse movimentado de cima para baixo, a direção da corrente no fio também seria inversa, indo de N para P. Já no segundo caso, Faraday discutiu sobre a relação da corrente elétrica induzida a partir do movimento de um fio vertical (P'N'), salientando que quando o fio fosse movimentando em torno do polo conforme a trajetória pontilhada, a corrente elétrica nele possuía direção de P' para N'. Além disso, Faraday também observou o comportamento da corrente elétrica quando o fio PN girava em torno do imã cilíndrico, ele encontrou a direção da corrente elétrica igualmente para esse caso.

Dessa forma, percebemos na lei de Faraday a ausência de qualquer formulação matemática, há apenas a descrição empírica e teórica do comportamento da corrente elétrica 
induzida em um condutor quando movimentado em torno de um ímã natural, principalmente quando ele intercepta perpendicularmente as 'curvas magnéticas' do imã, fato esse que Faraday mencionou novamente em trabalhos posteriores, reforçando que "[...] a lei sob qual a corrente elétrica é induzida em corpos movimentados relativamente a imãs, é feita dependente da interseção das curvas magnéticas pelo metal (114.)" (FARADAY, 1832, p. 186, tradução nossa). Assim, considerando a importância da teoria das curvas magnéticas de Faraday para uma real e significativa compreensão da sua lei, ela também deve aqui ser abordada e discutida.

Para Faraday, os imãs naturais, eletroímãs ou os fios percorridos por corrente elétrica eram circundados por certas linhas, denominadas de curvas magnéticas ou linhas de força magnética. No início de seus trabalhos, o conceito dessa sua teoria das curvas magnéticas não apareceu de maneira tão clara, como demonstra a definição apresentada neste seu primeiro artigo em nota de rodapé:

[...] por curvas magnéticas, eu quero dizer as linhas de força magnética, porém modificadas pela justaposição dos polos, que seriam retratadas por limalhas de ferro; ou aquelas [linhas] para qual a agulha magnética muito pequena, formariam uma tangente (FARADAY, 1832, p. 154, tradução nossa).

Com a falta de clareza para tal conceito no início de sua utilização, surgiram dúvidas e confusões quanto ao que de fato essas linhas representavam, assim como revelado pelo próprio Faraday quase após mais de 20 anos desde a publicação de sua lei: "3175. Enquanto escrevia este artigo [de número 28], eu percebi que, nas últimas Séries daquelas Pesquisas, Nos. XXV. XXVI. XXVII., eu tenho algumas vezes usado o termo linhas de força tão vagamente, [a ponto] de deixar o leitor duvidoso..." (FARADAY, 1852, p. 55, tradução nossa). No entanto, ao decorrer de sua série de Pesquisas Experimentais em Eletricidade, Faraday foi tratando tal assunto com um maior cuidado, e quase 20 anos após a publicação de sua lei, Faraday dedicou o número 28 de sua série (publicado em 1852) especialmente para abordar esse assunto e sanar as dúvidas que ainda existiam, apresentando, assim, uma definição mais trabalhada e formal quanto ao conceito de suas linhas de força magnética, salientando que não adentraria aos aspectos filosóficos quanto à natureza delas no trabalho em questão (apesar de mesmo assim ainda haver algumas breves discussões quanto as suas crenças e filosofia), conforme levantado por ele:

3075. Eu desejo restringir o significado do termo linha de força, de tal modo a implicar nada mais do que a condição da força em qualquer lugar dado, tanto quanto a força e direção; e não incluir (no presente) qualquer ideia com relação à natureza da causa física dos fenômenos; ou ser amarrada com, ou de qualquer forma dependente, a tal ideia (FARADAY, 1852, p. 26, tradução nossa).

Assim, Faraday buscou ser o mais claro possível, apresentando uma definição curta e objetiva, evitando, para esse momento, discutir os aspectos filosóficos que faziam parte de suas crenças e teorias com relação à natureza dos fenômenos. No entanto, levando em consideração a importância de tais aspectos para compreendermos em maior profundidade a sua teoria das linhas de força magnética, apresentamos brevemente algumas reflexões quanto ao contexto filosófico em que essa sua teoria está imersa.

Em suma, Faraday passou a atribuir, às linhas de força magnética, uma representação do estado (ou condição) da força, tanto em direção quanto em intensidade, força essa na qual, para Faraday, estaria mais inclinada e relacionada à ideia de uma transmissão por meio de um 
agente mediador do que simplesmente por ação a distância. Esse agente mediador poderia ser uma função do próprio meio físico no qual estaria a preencher todo o espaço (talvez o próprio éter), segundo Faraday:

\begin{abstract}
3075. [...] A conclusão geral dos filósofos parece ser que, tais casos são de longe os mais numerosos e, da minha própria parte, considerando a relação de um vácuo com a força magnética e o caráter geral dos fenômenos magnéticos externos ao imã, eu estou mais inclinado à noção de que na transmissão da força exista uma ação externa ao imã, do que os efeitos serem meramente atração e repulsão à distância. Tal ação [externa] pode ser uma função do éter; pois não é de todo improvável, se houver um éter, ele deve ter outros usos além do simples transporte de radiações (2591. 2787.) (FARADAY, 1852, p. 27, tradução nossa).
\end{abstract}

Sendo assim, percebemos que seja o agente mediador uma função do próprio meio ou não, a sua consideração nos leva diretamente à necessidade da existência de um meio físico no qual tal mediador possa atuar, pois, caso contrário, como seria possível existir um agente mediador (algo real) no espaço vazio? Uma vez que a própria ideia de vazio já nos remete que nele nada existe, muito menos um agente mediador da força. Tal crença é exposta por Faraday de maneira mais clara em trabalhos posteriores, salientando que: "3258. [...] eu não posso conceber as linhas curvadas de força sem as condições de uma existência física naquele espaço intermediário" (FARADAY, 1852, p. 408, tradução nossa).

É possível concluirmos que a concepção das linhas de força magnética de Faraday e, consequentemente, a sua lei da Indução Eletromagnética (114), está inserida num contexto muito mais complexo do que geralmente é apresentado, um contexto no qual é necessário pressupor a existência de um meio físico em todo o espaço, seja o éter ou não, para que ela não venha assim a perder sua ideia original e os alicerces filosóficos que a compõem, fatores esses que certamente levariam a uma compreensão inadequada de seu real sentido e valor.

Após Faraday ter enunciado sua lei da Indução Eletromagnética logo no início de sua série de Pesquisas Experimentais em Eletricidade e no Eletromagnetismo, apresentando novos experimentos, observações e conclusões com relação à Indução de Corrente Elétrica, ele continuou utilizando essa lei ao longo de outros trabalhos, até mesmo para lhe auxiliar em algumas de suas reflexões, tal como é possível detectar em suas próprias citações após mais de 20 anos de publicação. Em nossa pesquisa, detectamos 24 citações de Faraday a sua lei ao longo de sua série, em específico, nos parágrafos 43, 122, 140, 149, 150, 161, 166, 173, 182, 231, 235, 236, 240, 244, 2431, 3070, 3089, 3091, 3113, 3173, 3174, 3272 e 3328.

\title{
4 A apresentação da lei de Faraday em sites da web e vídeos do YouTube: uma análise sobre os equívocos e distorções presentes
}

Embasados pela análise histórica da lei de Faraday que realizamos, e metodologicamente pelos procedimentos da pesquisa bibliográfica conforme descritos por Salvador (1981), procuramos identificar, analisar e compreender como essa lei é abordada em sites da web e vídeos do YouTube, a fim de detectarmos os equívocos presentes nos mesmos.

Além da metodologia acima citada (em especial dos processos de leitura) para uma seleção e compreensão mais minuciosa dos conteúdos trazidos pelos sites e vídeos, tivemos em nosso confronto crítico o princípio de que os fatos (seja em qualquer área do conhecimento) devem ser contados ao leitor da maneira mais próxima e fidedigna possível do seu real contexto 
(científico, político, econômico ou social) e época, sem que haja uma estarrecedora transformação didática dos conteúdos.

Dentro do âmbito do Ensino de Ciências, essa aproximação pode ser alcançada por meio da História e Filosofia da Ciência, surgindo assim a considerável importância de seu uso (adequado) na Educação Científica, uma vez que tal inserção é capaz de desenvolver momentos mais envolventes, reflexivos e críticos, assim como salienta Matthews (1995, p. 165):

\footnotetext{
A história, a filosofia e a sociologia da ciência não têm todas as respostas para essa crise, porém possuem algumas delas: podem humanizar as ciências e aproximá-las dos interesses pessoais, éticos, culturais e políticos da comunidade; podem tornar as aulas de ciências mais desafiadoras e reflexivas, permitindo, deste modo, o desenvolvimento do pensamento crítico.
}

Desta forma, podemos dizer, de forma sucinta, que, para o desenvolvimento desse momento, fora realizada uma pesquisa bibliográfica sobre a lei de Faraday em fontes da Internet (sites e vídeos), tal como uma simples comparação entre 'o que foi' e 'o que é apresentado'. Como já dito, para essa comparação, partimos de princípios e teóricos (citados na introdução) que nos levaram a compreender o papel fundamental da História e Filosofia da Ciência para o desenvolvimento de leitores mais reflexivos e independentes criticamente.

\subsection{Os critérios de seleção}

Nessa pesquisa, selecionamos 7 sites da web e 7 vídeos do YouTube utilizando o termo de pesquisa 'lei de Faraday'. Devido ao cronograma da pesquisa e os prazos para o desenvolvimento de uma análise e apresentação parcial dos resultados, tal seleção ocorreu em dois momentos distintos, o primeiro no mês de abril (2019) e o segundo, no mês de outubro (2019). No entanto, nenhuma alteração sobre os critérios de seleção ocorreu nesse meio período, tendo sido aplicados os mesmos critérios em ambos os momentos. Além disso, foi mantido o mesmo processo de análise sobre os conteúdos, uma vez que os procedimentos metodológicos da pesquisa bibliográfica já tinham sido definidos e adotados, tal como o estabelecimento da análise histórica da lei de Faraday como o embasamento e referencial teórico para o confronto crítico. Assim sendo, consideremos o segundo momento de seleção e análise como uma continuação dos mesmos.

Para a seleção dos sites, o primeiro critério foi adotar a ordem como gerada pelo Google, critério esse adotado pelo simples fato de que, no momento da pesquisa, poderíamos ter sido um leitor em busca de aprender sobre assunto e, assim, tais sites teriam sido os primeiros com os quais também teríamos tido o contato e, muito provavelmente, os tomado como referencial teórico para nossa aprendizagem. Respeitando, posteriormente, os demais critérios, o segundo foi de selecionar apenas os sites que traziam um conteúdo direcionado aos alunos do Ensino Médio, ou seja, sem a linguagem matemática do Cálculo Diferencial e Integral. Por fim, o último critério adotado foi selecionar somente os sites que apresentassem o enunciado e a explicação da lei de Faraday em si, e não apenas aplicações ou resoluções de exercícios de maneira isolada. Os sete primeiros sites que satisfizeram tais critérios foram analisados. Já os sites que foram descartados não foram muitos, tais descartes tiveram como principal fator a presença do Cálculo Diferencial e Integral, como foi o caso do Wikipedia, site que apareceu no primeiro lugar da lista. 
Já para os vídeos, o primeiro critério foi realizar a pesquisa no YouTube com o filtro "classificar por número de visualizações" ativo, para seguir a ordem dos vídeos mais visualizados até os menos visualizados. Posteriormente, o segundo critério foi escolher apenas os vídeos que contivessem em seu título o termo 'lei de Faraday' e apresentassem o conteúdo direcionado aos estudantes do Ensino Médio. O terceiro critério foi selecionar os vídeos que não trouxessem apenas aplicações ou resoluções de exercícios com relação ao conteúdo, mas o enunciado e a explicação da lei de Faraday em si. Finalmente, a fim de analisarmos uma maior quantidade possível de canais, foi considerado o critério de não ser analisado mais de um vídeo de um mesmo canal. Os sete primeiros vídeos que satisfizeram tais critérios foram analisados. Já o número de vídeos que foram descartados foi consideravelmente grande, acarretando que os últimos vídeos selecionados estivessem na posição de número 38 e 39 . Dentre os principais fatores que levaram a esse número de descarte mais elevado do que os dos sites, encontram-se: a presença do Cálculo Diferencial e Integral, ausência do termo 'lei de Faraday' no título, ausência do enunciado da lei de Faraday (vídeos de apenas experimentação ou aplicação) e apresentação de conteúdo de química.

\subsection{Os sites e vídeos analisados}

Nesta secção, apresentamos os 7 sites e vídeos que foram analisados. Para que o artigo não se torne muito extenso, mostramos apenas o nome e a posição de cada um na plataforma pesquisada em seu respectivo momento de seleção, ou seja, em abril e outubro.

Quadro 1 - Apresentação sucinta dos SITES selecionados

\begin{tabular}{|c|c|c|c|}
\hline Nome & Site & Posição em abril & Posição em outubro \\
\hline SITE A & Toda Matéria & $2^{\circ}$ & $\mathrm{x}$ \\
\hline SITE B & Khan Academy & $3^{\circ}$ & $\mathrm{x}$ \\
\hline SITE C & Mundo Educação & $4^{\circ}$ & $\mathrm{x}$ \\
\hline SITE D & Só Física & $5^{\circ}$ & $\mathrm{x}$ \\
\hline SITE E & Info Escola & $6^{\circ}$ & $4^{\circ}$ \\
\hline SITE F & Brasil Escola & $\mathrm{x}$ & $5^{\circ}$ \\
\hline SITE G & Conhecimento Científico & $\mathrm{x}$ & \\
\hline
\end{tabular}

Fonte: Elaborado pelos autores, 2020. 
Quadro 2 - Apresentação sucinta dos VÍDEOS selecionados

\begin{tabular}{|c|c|c|c|}
\hline Nome & Vídeo & Posição em abril & Posição em outubro \\
\hline VÍDEO A & $\begin{array}{c}\text { Física - Indução } \\
\text { Eletromagnética: Lei de } \\
\text { Faraday }\end{array}$ & $2^{\circ}$ & $\mathrm{X}$ \\
\hline VÍDEO B & $\begin{array}{l}\text { Lei de Faraday - Indução } \\
\text { eletromagnética - } \\
\text { Eletromagnetismo Aula } \\
12 \text { - Prof. Marcelo Boaro }\end{array}$ & $6^{\circ}$ & $\mathrm{x}$ \\
\hline VÍDEO C & $\begin{array}{l}\text { Indução eletromagnética } \\
\text { Lei de Faraday }\end{array}$ & $13^{\circ}$ & $\mathrm{X}$ \\
\hline VÍDEO D & $\begin{array}{l}\text { V-1- Lei de Faraday - } \\
\text { introdução }\end{array}$ & $\mathrm{X}$ & $23^{\circ}$ \\
\hline VÍDEO E & $\begin{array}{l}\text { Gerando corrente elétrica } \\
\text { com um imã, lei de } \\
\text { Faraday }\end{array}$ & $\mathrm{X}$ & $30^{\circ}$ \\
\hline VÍDEO F & Lei de Faraday-Neumann & $\mathrm{x}$ & $38^{\circ}$ \\
\hline VÍDEO G & $\begin{array}{l}\text { Lei de Faraday e Lenz - } \\
\text { indução eletromagnética - } \\
\text { Magnetismo }\end{array}$ & $\mathrm{X}$ & $39^{\circ}$ \\
\hline
\end{tabular}

Fonte: Elaborado pelos autores, 2020.

4.3 Algumas das passagens analisadas: os equívocos presentes na apresentação do conteúdo 'lei de Faraday'

Nesta secção, por questão de espaço, apresentamos de maneira mais detalhada a análise de um dos sites e de um dos vídeos selecionados, exemplificando como ocorreu com os demais. No entanto, a fim de termos uma visão completa de toda a pesquisa, uma discussão mais geral e uma tabela sintetizadora foram dispostas na próxima secção.

\subsubsection{Análises e discussões: SITE B}

No SITE B, iniciamos a discussão analisando o seguinte excerto: "Aprender o que a Lei de Faraday significa e como usá-la para determinar a força eletromotriz induzida" (KHANACADEMY, [201-?]).

Já de início, é possível detectarmos o primeiro equívoco presente, relacionado ao objetivo da lei de Faraday. Ela é apresentada como sendo uma lei utilizada para se determinar a força eletromotriz induzida em um determinado local, mas, como a análise histórica nos mostrou, Faraday não fez nenhuma menção sobre a força eletromotriz.

No segundo trecho analisado, temos: "A Lei de Faraday, nomeada assim devido ao físico do século XIX Michael Faraday, relaciona a taxa de variação do fluxo magnético através de uma espira com a magnitude da força eletromotriz $\varepsilon$ induzida nela." (KHANACADEMY, [201-?]). Essa relação é expressa na Figura 3. 
Figura 3 - Expressão matemática da "lei de Faraday" apresentada apelo SITE B

$$
\mathcal{E}=\frac{\mathrm{d} \Phi}{\mathrm{d} t}
$$

Fonte: KHANACADEMY ([201-?]).

Na enunciação da "lei de Faraday", também é mostrada uma curta e direta definição, que é uma descrição da expressão matemática mencionada. Associar essa expressão à Faraday é um engano, pois o britânico não utilizou esse tipo de linguagem. Em seu enunciado, não aparecem os termos "taxa de variação", "fluxo magnético" e "força eletromotriz".

Além disso, o objetivo dessa expressão é apenas calcular a intensidade da força eletromotriz induzida, enquanto que o que importava para o físico inglês era o comportamento da corrente elétrica induzida em um caso especial, que é o momento em que um fio condutor retilíneo é movimentado ao redor do polo magnético de um imã, principalmente quando ele atravessa perpendicularmente as curvas magnéticas. Desse modo, também se perde a consideração feita por Faraday sobre a existência de um meio físico mediador, éter, na análise desse fenômeno.

Continuando com o texto, na seguinte passagem, temos: "Enquanto a Lei de Faraday nos diz a magnitude do FEM produzida, a Lei de Lenz nos diz a direção que a corrente fluirá. Ela estabelece que essa direção sempre irá se opor à variação do fluxo que a produz" (KHANACADEMY, [201-?]).

Novamente a lei de Faraday é relacionada indevidamente à FEM, e, ao atribuir à Lei de Lenz a informação sobre a direção da corrente, dá a entender de que a Lei de Faraday não faz menção a esse aspecto do fenômeno estudado, o que não é verdade, muito pelo contrário. Essa ideia se repete no trecho a seguir: "A lei de Lenz é tipicamente incorporada na lei de Faraday com um sinal de menos, a inclusão deste permite que o mesmo sistema de coordenadas seja usado por ambos, o fluxo e o FEM" (KHANACADEMY, [201-?]).

A incorporação da lei de Lenz na Lei de Faraday é desnecessária, uma vez que a direção da corrente elétrica também é discutida por essa última. Em muitos de seus trabalhos, Faraday analisou de modo mais amplo o comportamento da corrente elétrica induzida, tanto por um imã natural quanto por um fio retilíneo percorrido por corrente elétrica, antes mesmo da enunciação da lei de Lenz, em 1834. Abaixo, temos a quinta e última passagem analisada desse site:

\footnotetext{
O experimento chave que leva Michael Faraday a determinar sua Lei de Faraday foi bem simples. Ele pode ser facilmente replicado com um pouco mais do que os materiais que possuímos em casa. Faraday usou um tubo de papel com fio isolado enrolado ao redor para formar uma bobina. Um voltímetro foi conectado ao redor da bobina e a FEM induzida lida enquanto um ímã era passado através da bobina. A configuração está mostrada na Figura 2 [Figura 4] (KHANACADEMY, [201-?]).
} 
Figura 4 - Representação do “experimento de Faraday” apresentada pelo SITE B

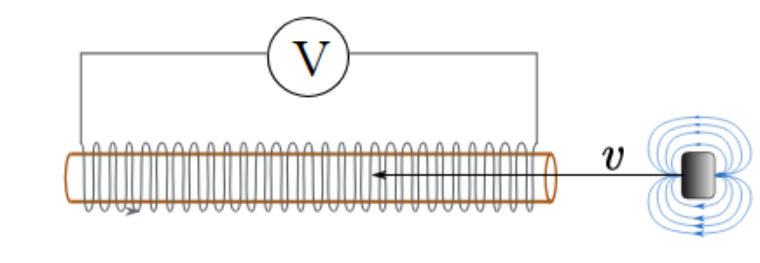

Figura 2: O experimento de Faraday: um ima é passado através de uma bobina.

Fonte: KHANACADEMY ([201-?]).

De início, o texto afirma que esse seria o experimento "chave" de Faraday para determinação de sua lei da Indução Eletromagnética. No entanto, mesmo que tal lei tivesse sido apresentada de forma adequada, ou seja, como foi de fato abordada por Faraday, diante da leitura e estudo dos relatos em seus diários de laboratório e de seus primeiros artigos relacionados à indução da corrente elétrica, não se sustenta dizer que esse foi um experimento decisivo para a elaboração de sua lei. Há um conjunto de outros importantes experimentos e situações que fizeram parte desse processo.

Além do mais, a descrição do experimento está equivocada, pois aparecem dispositivos e conceitos que não fizeram parte do experimento original, por exemplo, a utilização de um voltímetro e a concepção da força eletromotriz induzida.

\subsubsection{Análises e discussões: VÍDEO A}

Neste vídeo, encontramos logo no início uma breve descrição com relação ao período que antecedeu os estudos da indução de corrente elétrica por Faraday: "Na verdade, antes de se descobrir o fenômeno da indução, já se sabia que a carga elétrica em movimento gerava campo magnético" (FÍSICA - Indução Eletromagnética: Lei de Faraday, 2012). Esse é o primeiro engano apresentado, pois a concepção de campo magnético (assim como de campo elétrico) se consolida após a utilização de tal termo por Faraday, no ano de 1845, conforme ficou registrado em seu diário. O mais indicado seria afirmar que, antes do estudo do fenômeno da indução de corrente elétrica, era sabido que, em certas condições, havia uma relação entre corrente elétrica e um imã, fato esse que ficou ainda mais evidente com o desenvolvimento das rotações eletromagnéticas por Faraday. Por último, a sentença leva a crer que todos os cientistas, nessa época, acreditavam na teoria eletromagnética, o que está bem longe da realidade dos fatos.

Continuando com a nossa análise, temos o próximo trecho escolhido: "O segundo experimento que Faraday realizou, está aqui abaixo [Figura 5], ele tinha dois solenoides, o primeiro deles ligado a uma fonte de tensão, que podia fazer circular uma corrente por este solenoide, e uma chave para abrir e fechar o circuito" (FÍSICA - Indução Eletromagnética: Lei de Faraday, 2012). 
Figura 5 - Representação do “experimento de Faraday” apresentada pelo Vídeo A

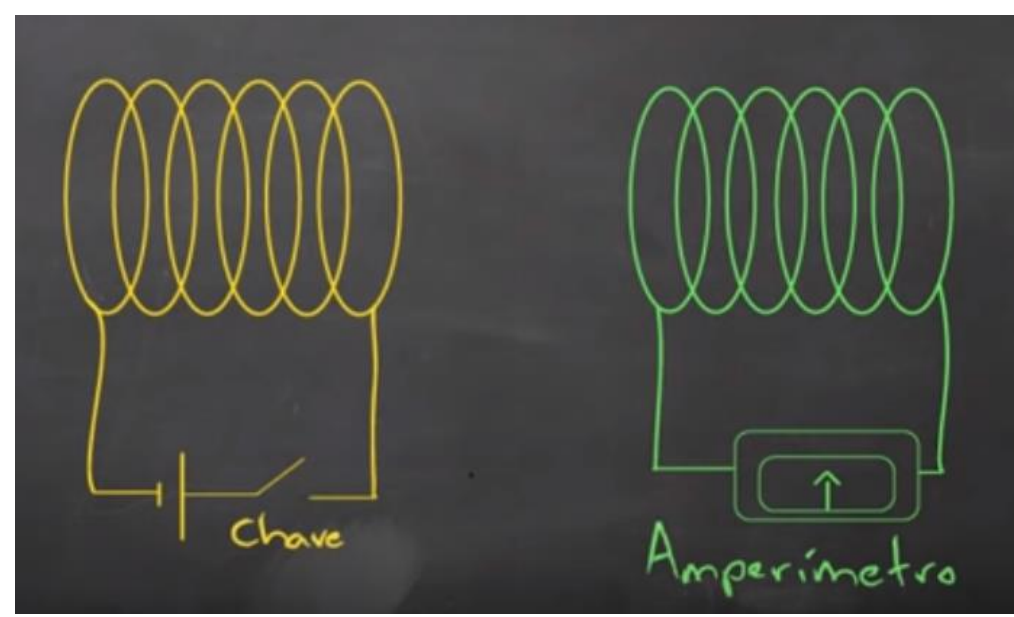

Fonte: FÍSICA - Indução Eletromagnética: Lei de Faraday (2012).

$\mathrm{Na}$ descrição do experimento em seu diário e em seu primeiro artigo da série de Pesquisas Experimentais em Eletricidade, Faraday não faz nenhuma menção à chave indicada na figura. Ele apenas menciona que a conexão era feita e rompida, levando a crer que tal procedimento se dava sem a utilização de uma chave, ou seja, se dava diretamente na bateria ou no solenoide, sem a presença de um dispositivo intermediário. Dando continuidade na descrição do experimento pelo vídeo, temos:

\begin{abstract}
Mas essa corrente logo voltava a ser zero, ela logo baixava, diminuía para zero de novo, era só no momento do fechamento da chave, e que surgia, o ponteiro batia no máximo e voltava pro zero, mostrando que a corrente só durou alguns instantes, a corrente só ia voltar a surgir quando a chave $\mathrm{C}$ era fechada, no momento em que a chave $\mathrm{C}$ era fechada, era desligado o campo magnético no solenoide, e surgia no outro solenoide, uma corrente no sentido contrário, que logo voltava pra zero, só no momento da abertura da chave, é que a corrente surgia, logo depois ela voltava a ser zero (FÍSICA - Indução Eletromagnética: Lei de Faraday, 2012).
\end{abstract}

De novo, de modo equivocado, surgem a utilização da chave e o conceito de campo magnético. Na passagem seguinte, temos um pequeno resumo das ideias apresentadas a partir da descrição do experimento de indução:

Então, era mais ou menos assim, quando o campo surgia, havia corrente, no momento em que surgia o campo, existia corrente no solenoide, no momento em que o campo ficava estável, não tinha nenhuma corrente nesse solenoide, sumia o campo nesse momento, surgia corrente, assim que se estabilizasse essa situação, a corrente voltava a ser zero (FÍSICA - Indução Eletromagnética: Lei de Faraday, 2012). descrito:

Em complemento, é afirmado o que seriam as conclusões de Faraday do experimento

O que Faraday conseguiu concluir é que sempre que surgia corrente no Amperímetro, sempre que surgia força eletromotriz induzida, o fluxo de campo magnético dentro desse solenoide aqui estava variando, e está a grande condição necessária para fazer 
o fenômeno magnético apresentar uma propriedade elétrica (FÍSICA - Indução Eletromagnética: Lei de Faraday, 2012).

Ainda se referindo aos experimentos realizados por Faraday, em 1831, período no qual ele obteve sucesso na análise do fenômeno da Indução de Corrente Elétrica, as concepções de força eletromotriz e campo magnético estão deslocadas temporalmente. A primeira foi tratada por Faraday apenas em 1840, em seus artigos de números 16 e 17, e a segunda se fez presente em seus trabalhos a partir do ano de 1845, ainda de maneira distinta da qual é apresentada hoje, uma vez que sua representação de campo tinha como base sua teoria das linhas de força.

O fato mais grave na afirmação citada é a omissão da condição encontrada por Faraday para que a Indução Eletromagnética ocorra, a saber: o movimento de um condutor em torno de um imã tem que ser de tal maneira que ele corte as 'linhas de força magnética' de forma perpendicular, ou seja, que o movimento forme assim um ângulo de $90^{\circ}$ com relação às tais linhas, ou com relação às suas tangentes, uma vez que essas linhas são curvas. No próximo trecho, há uma descrição do que seria a lei de Faraday:

A intensidade dessa força eletromotriz induzida, vai ser dada pela variação do fluxo, divido pelo intervalo de tempo onde ocorreu essa variação do fluxo, então a gente pode perceber dessa equação aqui, que é a lei de Faraday, essa equação ai [Figura 6] é a lei de Faraday, a gente pode ver a partir dela, que quanto maior for à variação de fluxo, maior vai ser a força eletromotriz induzida, enquanto menos tempo essa variação ocorrer, quanto mais brusca ela for, quanto menos for o tempo que ela demorar para acontecer, maior vai ser a força eletromotriz induzida (FÍSICA - Indução Eletromagnética: Lei de Faraday, 2012).

Figura 6 - Expressão matemática da "lei de Faraday" apresentada pelo Vídeo A

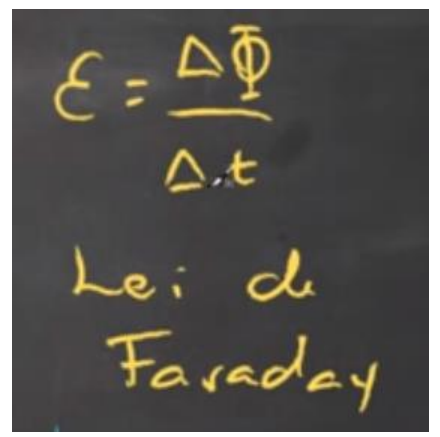

Fonte: FÍSICA - Indução Eletromagnética: Lei de Faraday (2012).

Assim como fez o Site B, a enunciação da "lei de Faraday" é feita como sendo uma descrição da equação matemática mencionada, incorrendo, dessa forma, nos erros citados e analisados anteriormente. O mesmo acontece quando a lei de Lenz é descrita como sendo um complemento necessário à lei de Faraday: "E vamos ver também a lei de Lenz, que é parte importante da lei de Faraday" (FÍSICA - Indução Eletromagnética: Lei de Faraday, 2012). Esse engano ocorre devido ao fato da própria lei de Faraday ser apresentada distorcida, pois em algumas de suas reflexões, como as que aparecem no final de seu primeiro artigo da série analisada, percebemos que a lei de Lenz não seria necessária para complementar a lei de Faraday. O físico inglês discorreu sobre o comportamento da corrente elétrica induzida, 
lembrando que, antes mesmo de 1834, Faraday já tinha realizado diversas reflexões quanto ao comportamento de oposição da corrente elétrica induzida com relação à corrente indutora.

\subsection{As convergências dos equívocos detectados: uma visão panorâmica da pesquisa}

Após essa análise mais detalhada de um site e de um vídeo entre os selecionados, apresentamos o quadro abaixo que contém uma síntese do que encontramos nos demais sites e vídeos que fizeram parte de nossa amostra. A categorização dos equívocos ocorreu a posteriori a análise, ou seja, fora estabelecida mediante o próprio surgimento dos equívocos, onde cada categoria se traduz em um equívoco em si.

Quadro 3 - Os equívocos e distorções emergentes da análise sobre a ‘lei de Faraday’ em sites da web e vídeos do YouTube

\begin{tabular}{|c|c|c|}
\hline \multicolumn{3}{|c|}{ Resumo dos equívocos detectados e das justificativas atribuídas } \\
\hline Equívoco & $\begin{array}{l}\text { Site/Vídeo que } \\
\text { apresenta o } \\
\text { equívoco }\end{array}$ & Justificativas \\
\hline $\begin{array}{l}\text { Apresentação de uma lei de } \\
\text { Faraday distorcida }\end{array}$ & $\begin{array}{l}\text { SITE A, B, C, D, } \\
\quad \text { E, F e G } \\
\text { VÍDEO A, B, C, } \\
\text { D, E, F e G }\end{array}$ & $\begin{array}{l}\text { - Utilização de uma linguagem } \\
\text { distinta da utilizada por Faraday; } \\
\text { - Utilização de conceitos que não } \\
\text { fazem parte do período em questão; } \\
\text { - Um contexto distinto e distante da } \\
\text { lei original; } \\
\text { - Um objetivo distinto da lei original. }\end{array}$ \\
\hline $\begin{array}{l}\text { Apresentação da lei de } \\
\text { Faraday apenas como uma } \\
\text { descrição da equação } \\
\text { matemática associada a ela }\end{array}$ & $\begin{array}{l}\text { SITE A, B, C, D, } \\
\quad \text { E, F e G } \\
\text { VÍDEO A, B, C, } \\
\text { D, E, F e G }\end{array}$ & $\begin{array}{l}\text { - Associação a uma equação } \\
\text { matemática que não é discutida por } \\
\text { Faraday. }\end{array}$ \\
\hline $\begin{array}{l}\text { Associação da lei de Lenz a } \\
\text { lei de Faraday como sendo } \\
\text { um complemento } \\
\text { fundamental para se } \\
\text { determinar o comportamento } \\
\text { e o sentido da corrente } \\
\text { elétrica induzida }\end{array}$ & $\begin{array}{l}\text { SITE B, C, D, E, } \\
\text { G } \\
\text { VÍDEO A, F, G }\end{array}$ & $\begin{array}{l}\text { - O comportamento e o sentido da } \\
\text { corrente elétrica induzida são } \\
\text { abordados por Faraday em sua lei e } \\
\text { em diversas reflexões ao longo de } \\
\text { seus trabalhos, até mesmo de } \\
\text { maneira mais geral. }\end{array}$ \\
\hline $\begin{array}{l}\text { Atribuição à lei de Faraday } \\
\text { como sendo uma derivação } \\
\text { da lei de Lenz }\end{array}$ & VÍDEO B & $\begin{array}{l}\text { - A lei de Faraday (1832) antecede a } \\
\text { lei de Lenz (1834), impossibilitando } \\
\text { que a lei de Faraday seja, assim, } \\
\text { consequência da lei de Lenz; } \\
\text { - As conclusões e reflexões realizadas } \\
\text { por Lenz em sua lei já tinham sido } \\
\text { também focos de discussões por } \\
\text { Faraday em seus estudos. }\end{array}$ \\
\hline
\end{tabular}




\begin{tabular}{|c|c|c|}
\hline & & $\begin{array}{l}\text { Apresentação de dispositivos, } \\
\text { objetivos e processos que não são } \\
\text { descritos por Faraday nos }\end{array}$ \\
$\begin{array}{c}\text { Descrição de experimentos } \\
\text { de forma distinta de como } \\
\text { realizados por Faraday }\end{array}$ & $\begin{array}{c}\text { SITE B } \\
\text { VÍDEO A }\end{array}$ & $\begin{array}{l}\text { Apresentação dos priginais; } \\
\text { episódios de maneira simplificada e } \\
\text { vaga, distorcendo os fatos reais. }\end{array}$ \\
\hline
\end{tabular}

Fonte: Elaborado pelos autores, 2020.

\section{Considerações Finais}

Em síntese, podemos afirmar que a lei da Indução Eletromagnética de Michael Faraday, conforme apresentada nos sites e vídeos analisados, é distinta da que o britânico enunciou em 1832, em seu primeiro artigo da série Pesquisas Experimentais em Eletricidade, e, posteriormente, em outros textos.

A partir da presente pesquisa, foi possível refletir um pouco sobre a credibilidade com que muitos conteúdos científicos estão sendo apresentados pela rede mundial de computadores. Desse modo, os resultados servem como um alerta aos professores e alunos que utilizam esses recursos como referenciais teóricos. Se não é possível, em curto prazo, modificar essas informações, tornando-as mais confiáveis, faz-se necessário um posicionamento mais crítico frente a elas, não as considerando como sendo inquestionáveis.

Dentre os caminhos que podem ser tomados para um desenvolvimento de leitores mais questionadores, céticos e preocupados a compartilhar conteúdos inequívocos e, assim, ir de encontro ao cenário acima levantado (a um longo prazo até modificá-lo consideravelmente mediante muita pesquisa e divulgações científicas concisas), está novamente a História e Filosofia da Ciência, uma vez que, e assim como já dito, o seu uso adequado na Educação Científica, seja num ambiente de ensino formal (básico e superior) ou informal, possui o potencial de estimular e desenvolver momentos realmente reflexivos e críticos, momentos em que a pessoa passa ser estimulada a questionar e obter respostas mais bem fundamentadas e coerentes aos seus 'porquês'.

\section{Referências}

BARRETO, E. R. L. A influência da Internet no processo de ensino-aprendizagem da leitura e da escrita. Revista Espaço Acadêmico, Maringá, v. 9, n. 106, p. 84-95, Mar. 2010.

BARROS, A. M.; CARVALHO, A. M. P. A história da ciência iluminando o ensino de visão. Revista Ciência \& Educação, Bauru, v. 5 n. 1, p. 83-94, 1998.

CARVAlHO, A. M. P. Construção do conhecimento e ensino de ciências. Em Aberto, Brasília, v. 11, n. 55, p. 9-16, Jul./Set. 1992.

CARVALHO, A. M. P. Contribuições para a introdução da História e Filosofia das Ciências no ensino das ciências tanto em Nível Médio como na formação de professores. Caderno Brasileiro de Ensino de Física, Florianópolis, v. 25, n. 1, p. 183-187, Abr. 2008. 
DIAS, V. S. Michael Faraday: subsídios para metodologia de trabalho experimental. 2004. 157f. Dissertação (Mestrado em Ensino de Ciências) - Instituto de Física, Universidade de São Paulo, São Paulo, 2004.

FARADAY, M.. Pesquisas experimentais em eletricidade (tradução de A. K. T. Assis e L. F. Haruna). Caderno Brasileiro de Ensino de Física, Florianópolis, v. 28, n. 1, p. 152-204, Abr. 2011.

FARADAY, M. Historical Sketch of Electro-magnetism. The Annals of Philosophy, London, v. 2, n. 3, p. 195-200, Sept. 1821.

FARADAY, M. Experimental researches in electricity ( $1^{\circ}$ series $)$. Philosophical Transactions Royal Society London, London, v. 122, p. 125-162, Jan. 1832.

FARADAY, M. Experimental researches in electricity ( $2^{\circ}$ series). Philosophical Transactions Royal Society London, London, v. 122, p. 163-194, Jan. 1832.

FARADAY, M. Experimental researches in electricity ( $28^{\circ}$ series). Philosophical Transactions Royal Society London, London, v. 142, p. 25-56, Jan. 1852.

FARADAY, M. On the Physical Character of the Lines of Magnetic Force. Philosophical Magazine and Journal of Science, London, v. 3, n. 20, p. 402-428, Jun. 1852.

FÍSICA - Indução Eletromagnética: Lei de Faraday. Pura Física. Youtube. 20 jul. 2012. 10min14s. Disponível em: <https://www.youtube.com/watch?v=yuRWx62DV54>. Acesso em: 22 abr. 2019.

GARDELLI, D. Experimento de Ørsted: subsídios para uma abordagem histórica do assunto no Ensino Médio. 2014. 206f. Tese (Doutorado em Educação para a Ciência e a Matemática) - Centro de Ciências Exatas, Universidade Estadual de Maringá, Maringá, 2014.

GOMES, L. C. Concepções alternativas e divulgação: análise da relação entre força e movimento em uma revista de popularização científica. 2008. 128f. Dissertação (Mestrado em Educação para a Ciência e o Ensino de Matemática) - Centro de Ciências Exatas, Universidade Estadual de Maringá, Maringá, 2008.

JONES, B. The life and letters of Faraday. London: Longmans, Green, and CO, 1870. (Vol. 2) $491 \mathrm{p}$.

KHANACADEMY. O que é Lei de Faraday? Disponível em: $<$ https://pt.khanacademy.org/science/physics/magnetic-forces-and-magnetic-fields/magneticflux-faradays-law/a/what-is-faradays-law>. Acesso: 29 de Abr. 2019.

LIMA, T. C. S.; MIOTO, R. C. T. Procedimentos metodológicos na construção do conhecimento científico: a pesquisa bibliográfica. Revista Katál, Florianópolis, v. 10, n. spe, p. 37-45, 2007.

MARTINS, R. A. Como não escrever sobre história da física: um manifesto historiográfico. Revista Brasileira de Ensino de Física, São Paulo, v. 23, n. 1, p. 113-119, Mar. 2001. 
MARTINS, R. A. A história das ciências e seus usos na educação. In: SILVA, Cibelle Celestino. (Org.). Estudos de história e filosofia das ciências: Subsídios para aplicação no Ensino. 1. ed. São Paulo: Editora Livraria de Física, 2006. p. 21-34.

MARTINS, R. A. Ørsted e a descoberta do eletromagnetismo. Cadernos de História e Filosofia da Ciência, Florianópolis, v. 10, n. 1, p. 89-114, 1986.

MARTINS, T. Faraday's diary: being the various philosophical notes of experimental investigation. D. C. L., F. R. S., 1820-1862. 7 vols. London: G. Bell and Sons, 1932-1936 (preview edition -2008.458 p).

MARTINS, T. Faraday's discovery of Electro-magnetic induction. London: Edward Arnold \& CO, 1949. 160p.

MATTHEWS, M. R. História, filosofia e ensino de ciências: tendência atual de reaproximação. Caderno Catarinense do Ensino de Física, Florianópolis, v. 12, n. 3, p. 164214, Dez. 1995.

NEVES, M. C. D. A história da ciência no ensino de física. Revista Ciência \& Educação, Bauru, v. 5, n. 1, p. 73-81, 1998.

ØRSTED, C. H. Thermo-electricity. The Edinburgh Encyclopedia, Edinburgh, v. 18, p. 573-89, 1830.

PEREIRA, M. B.; SOUZA, A. G.; PEIXINHO, K. F. M. A utilização da Internet como ferramenta de aprendizagem: o professor como inovador educacional. In: VI Colóquio Internacional "Educação e Contemporaneidade", 2, 2012, São Cristóvão. Anais... São Cristóvão: Universidade Federal de Sergipe, 2012. Disponível em:

<http://educonse.com.br/2012/eixo_08/PDF/60.pdf>. Acesso: 14 de Jan. 2020

RIBEIRO, J. E. A. Sobre a força de Lorentz, os Conceitos de Campo e a "Essência" do Eletromagnetismo Clássico. 2008. 114f. Dissertação (Mestrado em Ciências) - Instituto de Física, Universidade de São Paulo, São Paulo, 2008.

SALVADOR, A. D. Métodos e técnicas de pesquisa bibliográfica. $9^{\circ}$ ed. Porto Alegre: Editora Sulina, 1981.

SNELDERS, H. A. M. Oersted's discovery of electromagnetism. In: CUNNINGHAM, A.; JARDINE, N. Romanticism and the Sciences. Cambridge: Cambridge University Press, 1990.

THOMPSON, S. P. Michael Faraday: His life and work. New York: The Macmillan Company, 1898. 308p.

Recebido em março de 2020.

Aprovado em maio de 2020. 